УДК 316.628:330.342.146:364.658

\title{
ТЕОРИИ БЛАГОПОЛУЧИЯ И ИХ ОТРАЖЕНИЕ В СОВРЕМЕННЫХ ФИЛОСОФСКИХ КОНЦЕПЦИЯХ
}

\author{
Садовская Анна Александровна, \\ aastepanova@tpu.ru \\ Национальный исследовательский Томский политехнический университет, \\ Россия, 634050, г. Томск, пр. Ленина, 30.
}

Садовская Анна Александровна, аспирант, эксперт Отдела по работе с иностранными обучающимися Национального исследовательского Томского политехнического университета.

\begin{abstract}
Актуальность исследования проблемы благополучия в современной социальной философии вытекает из необходимости определения наиболее значимых трендов анализа данного феномена с последующим использованием полученных результатов для выстраивания оптимальной концепции социального благополучия современного общества. Цель работы: изучить зарубежные тренды в области исследования феномена благополучия, проанализировать существующие теории благополучия, а также выявить различные научные позиции по этому вопросу. Объектно-предметной областью исследования выступают современные концепты благополучия, представленные в работах Джона Стюарта Милля, Джереми Бентема, Роберта Нозика, Дерека Парфита, Ричарда Криспа, Джеймса Гриффина, Джона Финниса, Филипа Кичера, Томаса Хёрка, Марты Нуссбаум и других исследователей. Методы: аналитический и компаративный методы, которые позволили изучить основные научные тренды в области проблемы благополучия и сравнить результаты исследований российских и зарубежных авторов. Результаты. На основе анализа наиболее ангажированных теорий социального благополучия представлена классификация данных феноменов, проанализированы основные исследовательские тренды социального благополучия, определены дальнейшие шаги в исследовании благополучия.
\end{abstract}

Ключевые слова: Благополучие, гедонистические теории, теории исполнения желаний, объективные теории.

В настоящее время проблема благополучия является одной из самых обсуждаемых и актуальных в социальной философии. Ее востребованность определяется вопросами, которые ставит перед собой человек и общество в целом: что необходимо делать, чтобы быть успешным, в более широком смысле - как счастливо прожить жизнь. То, что положительно влияет на человеческое благополучие, приносит человеку пользу, является предметом его заинтересованности и обладает практической ценностью. То, что, напротив, оказывает отрицательное влияние, вредит человеку и является антиценностью. Современная философская литература, посвященная теме благополучия, в основном рассматривает оценочные теории благополучия, целью которых существует определение того, что в конечном счете заставляет людей чувствовать себя счастливыми и успешными, а что, напротив, ставит их в затруднительное положение. В современных исследованиях феномена благополучия принято выделять три основных вида понимания благополучия: гедонистические теории, теории исполнения желаний и объективные теории.

В соответствии с гедонистическими теориями, только удовольствие есть то, что истинно хорошо, а боль - что истинно плохо. Таким образом, жизнь человека склады- 
вается настолько удачно, насколько он способен накапливать удовольствие и избегать боли. Стремление к благополучию есть стремление к преобладанию удовольствия над болью. Современные гедонистические теории уходят корнями в работы таких философов, как Джон Стюарт Милль и Джереми Бентем, которые рассуждали о значении удовольствия в понятии благополучие.

Количественный, или простой, гедонизм - это теория, согласно которой «удовольствие определяется только его количеством (включая такие параметры, как продолжительность и интенсивность), а не качеством. Таким образом, источник удовольствия не является важным» [1, с. 121]. Данная теория была предложена Джереми Бентемом и подверглась суровой критике. Одним из критиков данной теории был Джон Стюарт Милль, заявивший о том, что «причина, по которой люди испытывают удовольствие, гораздо важнее его продолжительности» [2, с. 87]. Другими словами, если человек может удовлетворять только свои примитивные потребности и испытывать исключительно физическое удовольствие, нельзя говорить о том, что он проживает свою жизнь благополучно. Он лишает себя так называемого высшего удовольствия, которое он может получить от дружбы, получения знания, искусства и т. д. Таким образом, Милль выдвигает теорию качественного гедонизма, согласно которой некоторое высшее наслаждение является более ценным, чем низшее.

В работе современного американского философа Роберта Нозика дается критическая оценка гедонистических теорий как в количественной, так и в качественной формах [3]. Он заявил о том, что данные теории недостаточно отвечают на вопрос о том, что подразумевается под благополучной жизнью. Нозик называет жизнь «опытной машиной», которая использует нейростимуляцию для того, чтобы смоделировать несуществующий мир, или гедонизм, который обеспечивает пользователя беспрерывным наслаждением. Однако в таких условиях пользователь хоть и может испытывать любой вид наслаждения, но не может отличить вымышленное от реального. Нозик утверждает, что большинство людей выбрали бы не подключаться к подобной машине, т. к. они ценят события и опыт, который происходят в их реальных жизнях. Таким образом, теории гедонизма не раскрывают истинного значения благополучия.

Теории исполнения желаний, или теории удовлетворения потребностей, предполагают, что благополучие заключается в реализации человеческих желаний. Данные теории появились в XIX веке совместно с ростом интереса к экономике благосостояния. Экономисты хотели разработать объективные критерии для измерения благополучия у субъектов экономической деятельности. Поскольку удовольствие и боль измерить невозможно, экономисты решили рассмотреть удовольствие с точки зрения удовлетворения человеческих желаний. Таким образом, считается, что преимущество теорий исполнения желаний над гедонистическими теориями заключается в том, что они не принимают во внимание так называемую «опытную машину», а рассматривают реальные человеческие желания.

Американский ученый Р. Крисп формулирует три основные теории исполнения желаний [4]. Простая теория исполнения желаний (или теория исполнения желаний, существующих в определенный момент времени) предполагает, что человек чувствует себя лучше, когда его желания, существующие в данный момент времени удовлетворены, а если удовлетворены все человеческие желания, то считается, что прожита лучшая жизнь. Основной проблемой данной теории является то, что некоторые желания, которые человек имеет в определенный момент своей жизни, противоречат его долгосрочным интересам. К примеру, импульсивный подросток, совершающий какое-либо 
преступление, удовлетворяет свои краткосрочные желания, которые в долгосрочной перспективе будут работать против него.

Рефлексивная, или обстоятельная, теория исполнения желаний обращает внимание на рефлексивные, тщательно продуманные человеческие предпочтения. Согласно данной теории, если человек решает прожить долгую и счастливую жизнь, то данный его выбор возьмет верх над его краткосрочными желаниями, которые могут отрицательно сказаться на его цели. Отрицательным моментом данной теории является то, что человек не всегда делает выбор, оптимальный для него. Профессор Крисп приводит в пример сироту, который живет в монастыре и внезапно выигрывает в лотерею. Теперь перед ним стоит выбор: остаться в монастыре и отдать свой приз или выбрать новую жизнь за стенами монастыря. Но поскольку он не знает, какова жизнь за стенами монастыря, после долгих размышлений он все же решает вернуть свой приз. В данном случае очевидно, что сирота выбрал не лучшую альтернативу, т. к. он не был тщательно проинформирован о том, что ждет его, если он сделает другой выбор. Можно предположить, что рефлексивная теория также не дает полного представления о благополучии.

Информационная теория исполнения желания подразумевает, что человек живет наиболее благополучно тогда, когда удовлетворены все его желания с учетом всех возможных последствий. Таким образом, основная идея данной теории заключается в правильном информировании человека о том, что его ждет, если он сделает тот или иной выбор. Вследствие правильного информирования человек выбирает «умные» желания, которые всецело удовлетворяют как его краткосрочные, так и долгосрочные потребности.

Основное противоречие всех трех теорий исполнения желаний заключается в том, что они представляют абстрактную, формальную теорию благополучия, которая ничего не говорит о его источниках. Сторонники этих теорий отстаивают научную позицию о том, что удовлетворение наших желаний является необходимым условием благополучия, но они не принимают во внимание источники этих желания. Кроме того, теории исполнения желаний не раскрывают причины, почему определенные желания полезны для человека. В дополнение ко всему данные теории не рассматривают так называемые дефективные или непродуктивные желания, которые люди иногда выбирают даже будучи тщательно информированными о всевозможных последствиях. В данном случае возникает вопрос, правильно ли полагать, что удовлетворение подобных желаний улучшает качество жизни больше, чем если бы человек выбрал альтернативную опцию.

Исследователи, придерживающиеся объективных теорий, предполагают, что благополучие является результатом сущностных человеческих обстоятельств, нежели чем субъективного удовольствия или же исполнения субъективных желаний. Согласно данным теориям, существуют вещи, которые способствуют человеческому благополучию, вне зависимости от того, желаемы ли они или же просто приносят удовольствие. Благополучие измеряется исходя из того, насколько велик список подобных предметов в человеческой жизни. Данный список объективен, поскольку он увеличивает ценность человеческой жизни независимо от его предпочтений, характера или интересов.

В соответствии с научной позицией Дерека Парфита в указанную номенклатуру входят такие понятия, как доброта, нравственность, рациональная деятельность, воспитание детей, знания и понимание истинной красоты [5].

Джеймс Гриффин включает в этот список удовлетворение от проделанной работы, компоненты человеческого существования (независимость, способности и свобода), понимание, радость и глубокие личные взаимоотношения [6]. 
Джон Финнис предложил включить в данный список жизнь, знания, игру, эстетический опыт, дружбу, практическую разумность и религию [7].

Однако объективные теории могут различаться не только по разнообразию списков, включающих феномены человеческого благополучия, но и по причинам, которые определяют наличие того или иного понятия в определенном списке. Так, Филип Кичер предложил различать простые и разъяснительные объективные теории благополучия. Простые объективные теории благополучия представляют собой список понятий, которые не имеют единого, объединяющего их элемента. Каждое из них вносит свой вклад в благополучие индивида, независимо от других. Разъяснительные объективные теории благополучия, напротив, определяют фундаментальный элемент, который объединяет все понятия в списке и объясняет, как и почему они влияют на благополучие. Большинство современных объективных теорий являются разъяснительными [8].

Одними из наиболее влиятельных разъяснительных объективных теорий является перфекционизм. Согласно данным теориям, главное, что объединяет предметы определенного списка - это их вклад в совершенствование человеческой природы. Таким образом, теории перфекционизма побуждают людей прилагать усилия для совершенствования своих способностей, будь то искусство, наука, культура, спорт или повседневная жизнь.

Одной из наиболее известных теорий перфекционизма является Аристотелевская теория высшего блага, которое он называл эвдемонизмом. Согласно данной теории, «человеческое благополучие заключается в культивации человеческих добродетелей и рациональности, что неизбежно приведет к высшему благу» [9, с. 148]. Томас Хёрка (1993) представил неоаристотельскую теорию перфекционизма. Он утверждал, что человеческая природа характеризуется тремя видами совершенства. Физическое совершенство означает оптимально функционирование наших биологических систем. Теоретическое и практическое совершенство есть оптимальное развитие наших устремлений, а также оптимальный способ претворения их в жизнь. Благополучие реализуется посредством физического, теоретического и практического совершенства индивида [10].

Марта Нуссбаум, развивая идеи Аристотеля о высшем благе, представила теорию возможностей, неоаристотельскую теорию, согласно которой благополучие зависит от реальных возможностей и способностей человека, таких как умение читать, быть здоровым, заботиться о других и т. д. Она разработала 10 основных способностей, которые она считает наиболее необходимыми для достижения благополучия и которые происходят из человеческой природы: телесное здоровье, телесная неприкосновенность, рациональное восприятие, игра и др. М. Нуссбаум утверждает, что не обязательно обладать всеми десятью возможностями, главное, выбрать те, которые наиболее важны для отдельного индивидуума [11].

Обоснованная критика объективных теорий заключается в том, что в рамках этих теоретических дискурсов людям навязываются вещи, которые хоть и являются полезными для них, но совершенно не совпадают с их собственными желаниями или ценностями. Данные теории отрицают тот факт, что все люди разные и что различные ситуации могут по-разному влиять на них. Кроме того, объективные теории часто включают в свои списки, влияющие на благополучие совершенно несравнимые понятия. Может ли жизнь, в которой нет места дружбе, но есть место большому количеству знаний, быть лучше жизни, в которой достаточно дружбы, но нет знаний?

Таким образом, можно сделать вывод о том, что ни одна из заявленных теорий благополучия не совершенна. В настоящее время философы по всему миру пытаются выйти из тупиковых ситуаций, которые стоят в каждой из вышеописанных теорий. Ни- 
же мы рассмотрим различные точки зрения современных ученых на понятие «благополучия» и попытаемся определить, какая из вышеперечисленных теорий является ключевой в настоящее время.

Интерес к теоретическому осмыслению феномена благополучия нашел отражение в работах М. Селигмана [12]. В его исследованиях выделены пять главных элементов благополучия: вовлеченность, смысл, положительные эмоции, достижения, отношения с другими людьми. Данные элементы он предлагает разделять на объективные и субъективные оценки благополучия. Кроме того, он заявляет о том, что на протяжении всей своей жизни человек постоянно вынужден принимать решение, благодаря которому он мог бы быть наиболее успешен по каждому элементу.

Т. Рат и Дж. Хартер выделяют следующие составляющие благополучия: профессиональное благополучие (карьера, призвание), физическое благополучие (крепкое здоровье), социальное благополучие (важность ближайшего окружения и социальных взаимоотношений), финансовое благополучие (финансовая безопасность, удовлетворенность своим уровнем жизни), благополучие в среде проживания (безопасность, собственный вклад в развитие общества).

Т. Рат и Дж. Хартер поддерживают идею М. Селигмана и утверждают, что человек старается преуспеть во всех заявленных составляющих благополучия, т. к. положительные результаты в одной из областей не могут возместить неудачу в другой [13]. Отсюда следует вывод о том, что авторы данных работ в своих исследованиях опираются на объективную теорию благополучия и теорию исполнения желаний, т. к., с одной стороны, они заявляют о том, что человек на протяжении всей жизни должен принимать решения, которые, по его мнению, способствуют его благополучию, с другой что есть вещи, объективно способствующие его достижению.

Эд Динер ввел такой термин, как «Субъективное благополучие» (Subjective WellBeing - SBW), который он понимает как переживание положительных эмоций, низкий уровень неприятных эмоций и высокий уровень удовлетворенности жизнью. Кроме того, он выделил четыре основных его компонента: удовлетворенность жизнью, удовлетворенность в конкретных сферах жизни, позитивный и негативный аффекты. Удовлетворенность жизнью и удовлетворенность в конкретных сферах жизни основываются на оценочных установках своей жизни [14]. На основании данного представления У. Шиммак предложил концепцию восходящих и нисходящих теорий. Согласно первой теории, удовлетворенность человека жизнью в целом зависит от оценки своей удовлетворенности в отдельных сферах жизни. Во второй теории говорится о противоположной причинно-следственной связи: удовлетворенность жизнью в целом является неотъемлемым условием для удовлетворенности в отдельных сферах жизни [15]. Из сказанного становится очевидным, что оба автора придерживаются объективной теории благополучия, т. к. согласно данной теории существуют вещи, которые способствуют человеческому благополучию, и оно измеряется исходя из того, насколько велик список подобных предметов в человеческой жизни. По мнению Э. Динера и У. Шиммака, удовлетворенность жизнью и удовлетворенность в конкретных сферах жизни основываются на оценочных установках своей жизни. Соответственно, чем больше данных установок, тем выше уровень удовлетворенности.

Дж. Мур предлагал отделять «личное благо» от «общественного», при этом критикуя само существование идеи «личного блага». По его мнению, «личное благо», а именно то, что хорошо только для одного человека, не имеет никакого смысла. Кроме того, он считал что «личное благо» состоит из удовольствия, что демонстрировало достаточно узкое представление об этом понятии [16]. 
Р. Краут ответил на высказывание Дж. Мура о том, что «личное благо» не имеет смысла и привел в пример следующую ситуацию: если в мире живет человек, чья жизнь стоит того чтобы жить, что само по себе не является благом, согласно Дж. Муру, однако данная жизнь является благом для самого человека, который ее проживает. Следовательно, этот факт является непосредственным обоснованием для существования такого мира. Таким образом, можно сделать вывод о том, что «личное благо» способствует развитию «общественного блага» [17].

Эта мысль продолжается в трудах Т. Скэнлона. Он, напротив, заявляет о том, что благополучие в философском смысле не подразумевает так называемую «сферу компенсацию», а именно отказ от одного блага во имя другого, которым можно будет воспользоваться только в далеком будущем [18].

Таким образом, Дж. Мур, Р. Краут и Т. Скэнлон также придерживаются объективной теории благополучия, т. к. в одном из постулатов данной теории говорится о том, что под благополучием понимается вклад каждого индивида в совершенствование человеческой природы, т. е., другими словами, в развитие «общественного блага».

На основании проведённого анализа можно сделать вывод о том, что многие зарубежные исследователи акцентируют свое внимание на выявлении основных составляющих благополучия, выявляют его особенности и порождают теории его функционирования. Проблемы социального благополучия, как феномена, способного в значительной степени улучшить качество жизни населения России рассматриваются в работах ученых Томского политехнического университета. Авторы статьи «Феномен благополучия: исследовательские парадигмы поколения 50х годов» уделяют особое внимание социальному благополучию пожилых людей и выделяют следующие аспекты, влияющие на него:

1. Система социального обеспечения и здравоохранения;

2. Система социального обслуживания населения и государственного и муниципального жилищного строительства;

3. Меры антициклической политики и государственное регулирование экономического развития;

4. Меры по защите окружающей среды. [19]

Научный концепт благополучия в исследованиях российских ученых включает в себя такие фундаментальные человеческие потребности как безопасность, поддержание собственного состояния здоровья на высоком уровне, правильное питание, самореализация, развитие социальных отношений, способствующих решению психосоциальных проблем. Таким образом, научная модель благополучия, особенно пожилых людей, включает в себя физические, социальные, эмоциональные и когнитивные компоненты. [20]

На основании всего вышесказанного можно сделать вывод о том, что в настоящее время превалирующей теорией является объективная теория благополучия. На наш взгляд, это обусловлено тем, что она является более перспективной траекторией исследования благополучия в социально-философских позициях.

Анализ основных исследовательских трендов социального благополучия, представленный в работах зарубежных и российских ученых, отчетливо демонстрирует востребованность в анализе феномена благополучия с целью выявления потенциальных возможностей использования этих наработок в программах, способных обеспечить более высокий уровень жизни населения нашей планеты. В благополучном мире люди объективно стали жить лучше. 
Благополучие понимается не только как экономическое или материальное, но и как социальное. Автор данной статьи считает, что дальнейший шаг в исследовании благополучия должен быть связан с пониманием, исследованием и оценкой идеалов социального благополучия.

\section{СПИСОК ЛИТЕРАТУРЫ}

1. Bentham J. An Introduction to the Principles of Morals and Legislation. URL: https://www.earlymoderntexts.com/assets/pdfs/bentham1780.pdf (дата обращения: 12.12.2018)

2. Mill J.S. Utilitarianism. URL: https://www.earlymoderntexts.com/assets/pdfs/mill1863.pdf (дата обращения 12.12.2018).

3. Nozick R. Anarchy, state and utopia. - New York: Basic Books, 1974. - 334 p.

4. Crisp R. Reasons and the Good. - Oxford: Oxford University Press, 2008. - 192 p.

5. Parfit D. Reasons and Persons. - Oxford: Oxford University Press, 1984. URL: https://commonweb. unifr.ch/artsdean/pub/gestens/f/as/files/4610/17613_101712.pdf (дата обращения 12.12.2018).

6. Griffin J. Well-Being: Its Meaning, Measurement and Moral Importance. - Oxford: Clarendon Press, 1986.$412 \mathrm{p}$.

7. Finnis J. Natural Law and Natural Rights - Oxford: Clarendon Press, 1980. URL: http://bookre.org/ reader?file=1441762\&pg=4 (дата обращения 07.02.2019).

8. Kitcher Philip. Essence and Perfection // Ethics. - 1999. - V. 110. - № 1. - pp. 59-83.

9. Aristotle's Metaphysics. URL: https://plato.stanford.edu/entries/aristotle-metaphysics/ (дата обращения 07.02.2019).

10. Hurka T. Perfectionism. - Oxford: Oxford University Press, 1993. - 234 p.

11. Nussbaum M.C. Women and Human Development: The Capabilities Approach. - Cambridge: Cambridge University Press, 2000. URL: https://genderbudgeting.files.wordpress.com/2012/12/nussbaum_women_ capabilityapproach2000.pdf (дата обращения 07.02.2019).

12. Селигман М. Путь к процветанию. Новое понимание счастья и благополучия. - М.: МИФ, 2013. $440 \mathrm{c}$.

13. Rath T., Harter J. Wellbeing: The Five Essential Elements. - New York: GALLUP Press, 2010. - 232 p.

14. Diener E. Subjective well-being // Psychological Bulletin. - 1984. - V. 95. - № 3. - pp. 542-575.

15. Schimmack U. The structure of subjective well-being / Eds. M. Eid, R.J. Larsen // The Science of Subjective Well-Being. - New York: Guilford Press, 2008. - pp. 97-123.

16. Moore G.E. Principia Ethica - Cambridge: Cambridge University Press, 1994. -352 p.

17. Kraut R. What is Good and Why. The Ethics of Well-Being. - Cambridge: Harvard University Press, 2007. $-304 \mathrm{p}$.

18. Scanlon T. What We Owe to Each Other. - Harvard: Belknap Press, 1999. - 432 p.

19. Well-being as a Phenomenon: Research Paradigms of the Fifth Age / O.T. Loyko et al. // The European Proceedings of Social \& Behavioural Sciences (EpSBS) (11-16 September 2016, Tomsk, Russian Federation). - Tomsk, 2017. - V. 19. - P. 438-443.

20. Барышева Г.А., Аксёнова Ю.В., Сытых М.С. Сравнительное исследование благополучия пожилых людей на основе показателей г. Томска и г. Бремена с помощью эконометрической регрессионной модели // Вестник Томского государственного педагогического университета. - 2014. - Вып. 5 (146). C. $170-176$.

21. Beskrovnaya L.V., Kovalenko N.A., Chalov D.V. Social Wellbeing of Older Adults in Britain and Russia through the Prism of Social Challenges // The European Proceedings of Social \& Behavioural Sciences (EpSBS) (11-16 September 2016, Tomsk, Russian Federation). - Tomsk, 2017. - V. 19. - P. 83-89.

22. Щекотин Е.В. Проблема благополучия в турбулентном социуме: аспект безопасности // Вестник науки Сибири. - 2017. - Вып. 4 (27). - С. 74-83.

23. Alexandrova A. A Philosophy for the Science of Well-being. - New York: Oxford University Press, 2017. $248 \mathrm{p}$.

Поступила 10.02.2019 2. 


\title{
THE WELL-BEING THEORIES AND THEIR REFLECTION IN CONTEMPORARY PHILOSOPHICAL CONCEPTS
}

\author{
Anna A. Sadovskaya, \\ aastepanova@tpu.ru \\ National Research Tomsk Polytechnic University, \\ 30, Lenin Avenue, Tomsk, 634050, Russia.
}

Anna A. Sadovskaya, postgraduate student, exchange coordinator, National Research Tomsk Polytechnic University.

The relevance of well-being study in modern social philosophy results from the need to determine the most significant trends in the analysis of this phenomenon, followed by the use of the results to identify an optimal concept of social well-being in modern society. The main aim of the research is to study foreign trends in the study of well-being phenomenon, to analyze the existing theories of well-being and to identify various scientific positions on this issue. The object-subject area of research is modern concepts of well-being presented in the works of John Stuart Mill, Jeremy Bentham, Robert Nozik, Derek Parfit, Richard Crisp, James Griffin, John Finnis, Philip Kitcher, Thomas Herk, Martha Nussbaum etc. Methods. This article uses analytical and comparative methods, which allow studying the main scientific trends in the field of well-being and comparing the results of domestic and foreign authors research. Results. The paper presents the classification of the most relevant theories of social well-being, analyses main research trends of this phenomenon and determines further steps in well-being study.

Key words: Well-being, hedonism theories, desire fulfillment theories, objective theories.

\section{REFERENCES}

1. Bentham J. An Introduction to the Principles of Morals and Legislation. Available at: https://www.earlymoderntexts.com/assets/pdfs/bentham1780.pdf (accessed 12 December 2018).

2. Mill J.S. Utilitarianism. Available at: https://www.earlymoderntexts.com/assets/pdfs/mill1863.pdf (accessed 12 December 2018).

3. Nozick R. Anarchy, state and utopia. New York, Basic Books Publ., 1974. 334 p.

4. Crisp R. Reasons and the Good. Oxford, Oxford University Press, 2008. 192 p.

5. Parfit D. Reasons and Persons. Oxford, Oxford University Press, 1984. Available at: https://commonweb.unifr.ch/artsdean/pub/gestens/f/as/files/4610/17613_101712.pdf (accessed 12 December 2018).

6. Griffin J. Well-Being: Its Meaning, Measurement and Moral Importance. Oxford, Clarendon Press, 1986. $412 \mathrm{p}$.

7. Finnis J. Natural Law and Natural Rights. Oxford, Clarendon Press, 1980. URL: http://bookre.org/reader?file=1441762\&pg=4 (accessed 7 February 2019).

8. Kitcher Philip. Essence and Perfection. Ethics, 1999, vol. 110, no. 1, pp. 59-83.

9. Aristotle's Metaphysics. URL: https://plato.stanford.edu/entries/aristotle-metaphysics/ (accessed 7 February 2019).

10. Hurka T. Perfectionism. Oxford, Oxford University Press, 1993. 234 p.

11. Nussbaum M.C. Women and Human Development: The Capabilities Approach. Cambridge, Cambridge University Press, 2000. URL: https://genderbudgeting.files.wordpress.com/2012/12/nussbaum_women_ capabilityapproach2000.pdf (accessed 7 February 2019).

12. Seligman M. Put k protsvetaniyu. Novoe ponimanie shchastya i blagopoluchiya [The path to prosperity. New understanding of happiness and well-being]. Moscow, MIF Publ., 2013. 440 p.

13. Rath T., Harter J. Wellbeing: The Five Essential Elements. New York, GALLUP PRESS, 2010. 232 p. 
14. Diener E. Subjective well-being. Psychological Bulletin, 1984, vol. 95, no. 3, pp. 542-575.

15. Schimmack U. The structure of subjective well-being. Eds. M. Eid, R.J. Larsen. The Science of Subjective Well-Being. New York, Guilford Press, 2008. pp. 97-123.

16. Moore G.E. Principia Ethica. Cambridge, Cambridge University Press, 1994. 352 p.

17. Kraut R. What is Good and Why. The Ethics of Well-Being. Cambridge, Harvard University Press, 2007. 304 p.

18. Scanlon T. What We Owe to Each Other. Harvard, Belknap Press, 1999. 432 p.

19. Loyko O.T. et al. Well-being as a Phenomenon: Research Paradigms of the Fifth Age. The European Proceedings of Social \& Behavioural Sciences (EpSBS) (11-16 September 2016, Tomsk, Russian Federation). Tomsk, 2017, vol. 19. pp. 438-443.

20. Barysheva G.A., Aksenova Yu.V., Sytykh M.S. Comparative study of well-being of older people on the basis of indicators of Tomsk and the city of Bremen using econometric regression model. Tomsk State Pedagogical University Bulletin, 2014, vol. 5 (146), pp. 170-176. In Rus.

21. Beskrovnaya L.V., Kovalenko N.A., Chalov D.V. Social Wellbeing of Older Adults in Britain and Russia through the Prism of Social Challenges. The European Proceedings of Social \& Behavioural Sciences (EpSBS) (11-16 September 2016, Tomsk, Russian Federation). Tomsk, 2017, vol. 19. pp. 83-89.

22. Shchekotin E.V. The problem of well-being in a turbulent society. Bulletin of the Tomsk Polytechnic University, 2017, iss. 4 (27), pp. 74-83. In Rus.

23. Alexandrova A. A Philosophy for the Science of Well-being. New York, Oxford University Press. 248 p.

Received: 10 February 2019. 